\title{
Urinary Tract Infections Caused by Staphylococcus saprophyticus and their antimicrobial sensitivity pattern in Young Adult Women
}

\author{
Sanya Tahmina Jhora, ${ }^{1}$ Shikha Paul ${ }^{1}$ \\ ${ }^{1}$ Department of Microbiology, Sir Salimullah Medical College.
}

\begin{abstract}
The present study was conducted to observe the antibiotic sensitivity pattern of isolated S. saprophyticus from urine samples of patients admitted in inpatient department or visited the out patient department of Sir Salimullah Medical College \& Mitford Hospital (SSMC\& MH) Dhaka from October 2002 to September 2003. Among the isolates, Esch. coli was the most predominant $(82.61 \%)$ urinary pathogens followed by $S$. saprophyticus $(\mathbf{7 . 0 1 \% )} .93 .10 \% S$. saprophyticus was isolated from females of which highest $(\mathbf{4 4 . 8 2} \%)$ rate of isolation was among female of $18-45$ years age group. Rate of isolation was also high $\mathbf{( 4 1 . 3 8 \% )}$ among female of $<18$ years age group. All strains of $S$. saprophyticus $(\mathbf{1 0 0 \% )}$ ) were sensitive to Imipenem. High sensitivity was also observed to gentamicin $(86.20 \%)$ and ceftriaxone $(\mathbf{7 2 . 4 1 \%}$ ). Ciprofloxacin was found to be sensitive against $\mathbf{6 8 . 9 6 \%}$ isolates. Sensitivity of ceftazidime, cephalexin and cloxacillin were $\mathbf{6 5 . 5 1 \% , 5 5 . 1 7 \%}$ and $55.17 \%$ respectively. However, most of the $S$. saprophyticus are resistant to ampicillin, nalidixic acid and cotrimoxazole. So, the present study illustrates that physicians and microbiologists must be aware that $\boldsymbol{S}$ saprophyticus is an important cause of UTIs in young women and there is a need for continuous evaluation of common antibiotics used in the therapy of uropathogens.
\end{abstract}

Key Words: UTI, Staphylococcus saprophyticus

\section{Introduction}

Urinary tract infection (UTI) is the second most common infection in community practice. UTI refers to the presence of micro-organism in the urinary tract including urinary bladder, prostate, collecting system or kidney. The syndrome ranges from asymptomatic bacteriuria to perinephric abscess with sepsis ${ }^{1}$. Worldwide, about 150 million people are diagnosed with UTI each year costing the global economy in excess of 6 billion US dollars ${ }^{2}$. All over the world, Esch. coli accounts for $75 \%$ to $90 \%$ of UTI isolates and S. saprophyticus accounts for $5 \%$ to $15 \%$ of cases of uncomplicated cystitis ${ }^{3}$. Coagulase-negative staphylococci were considered to be urinary contaminants prior to the 1960s. In 1962 the isolation of coagulase-negative staphylococci possessing antigen 51 from the urine of women with acute UTI had been reported ${ }^{4,5}$. Urease production is another important characteristic, and

\section{Correspondence:}

Professor Dr. Sanya Tahmina Jhora

Department of Microbiology,

Sir Salimullah Medical College.

E.mail-saniatahmina@yahoo.com renal and ureteral stones were found to be associated with $S$. saprophyticus infection ${ }^{6}$. In the early 1970 s, this species became recognized as a frequent cause of urinary tract infections. ${ }^{3}$ The microorganisms colonize the human gastrointestinal tract, particularly during the summer and fall season. Other associations include outdoor swimming prior to colonization and occupations related to meat processing and meat products. S. saprophyticus has been isolated from 7.1\% of rectal swab specimens taken from carcasses of cattle ${ }^{7}$. The organism may be present on normal skin and in the periurethral and urethral region transiently and in small number ${ }^{8}$. Several studies showed that rectal, vaginal, and urethral colonization of $S$. saprophyticus was associated with UTI caused by this organism ${ }^{9}$. The bacteria may also reside in the urinary tract and bladder of sexually active females ${ }^{10}$. The bacterium has a capacity for selective adherence to human urothelium. It causes direct hemagglutination. The adhesin for S.saprophyticus is a lactosamine structure. This staphylococcal species produces an extracellular enzyme complex that can inhibit growth of both gram-positive and gram-negative bacteria such as Neisseria gonorrhoeae and $S$. aureus $^{3,8}$. 
S. saprophyticus is second only to E. coli as the most frequent causative organism of uncomplicated UTI in women. The vast majority of infections occur in young sexually active women ${ }^{11,12}$. It is referred to as "honeymooner's" UTI due to its association with intercourse. There are also several case reports of infections in young girls ${ }^{13}$. The more severe complications include acute pyelonephritis, septicemia, nephrolithiasis and endocarditis $7,14,15$. S. saprophyticus can also cause UTI in males of all ages; the organism has been isolated in young boys, male homosexuals, and elderly men with indwelling urinary catheters ${ }^{16,17}$. It also can cause urethritis,epididimitis, prostatitis, and nephrolithiasis in men, and is relatively rare in hospitalized men ${ }^{18}$.

S. saprophyticus is usually susceptible to antibiotics commonly prescribed for patients with UTI, with the exception of nalidixic acid. Furthermore, in women with acute uncomplicated cystitis, empirical therapy without a urine culture is often used. The rationale for this approach is based on the highly predictable spectrum of etiologic agents causing UTI and their antimicrobial resistance patterns. However, antimicrobial resistance among uropathogens causing community-acquired UTIs, both cystitis and pyelonephritis, is increasing ${ }^{19}$. Combination of sulfamethoxazole and trimethoprim was once the first-line antibiotic for use in Staph UTIs because it is inexpensive, is effective against $S$. saprophyticus and is excreted in active form in urine. ${ }^{20}$ Fluoroquinolones are preferred as initial agents for empiric therapy of UTI in areas where resistance is likely to be of concern ${ }^{20,21}$. So, isolation \& identification of urinary pathogens with their sensitivity pattern should be done routinely.

The present study has documented the distribution of urinary pathogens \& the antimicrobial sensitivity pattern of isolated S. saprophyticus in Sir Salimullah Medical College Mitford Hospitals, Dhaka.

\section{Materials \& Methods:}

This study was done in the department of Microbiology, Sir Salimullah Medical college, Dhaka from October 2002 to September 2003. Urine samples were collected from patients either admitted in inpatient department or visited the out patient department of Sir Salimullah Medical College \& Mitford Hospital (SSMC\& MH) Dhaka. The patients comprised both sexes \& all age groups. Mid-stream clean catch urine was collected by standard procedures. Semiquantitative culture was done on blood agar \& MacConkey agar media. Gram positive organisms were identified by catalase test, coagulase test and Novobiocin sensitivity test. Sensitivity pattern of the isolated organisms was determined by modified Kirby-Bauer technique using Mueller-Hinton $\operatorname{agar}^{22}$. The antibiotic discs used in

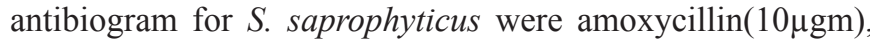
cloxacillin $(5 \mu \mathrm{gm})$, co-trimoxozole $(25 \mu \mathrm{gm})$, tetracycline
$(10 \mu \mathrm{gm}), \quad$ gentamicin $(10 \mu \mathrm{gm}), \quad$ ciprofloxacin $(5 \mu \mathrm{gm})$, cephalexin $(30 \mu \mathrm{gm})$, ceftriaxone $(30 \mu \mathrm{gm})$, ceftazidime $(30 \mu \mathrm{gm})$, nalidixic acid $(30 \mu \mathrm{gm})$, nitrofurantoin $(300 \mu \mathrm{gm})$

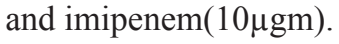

\section{Result:}

Table I showed the frequency of isolated bacteria from urine samples.A total 414 organisms were isolated of which Esch. coli was the most predominant $(82.61 \%)$ followed by $S$. saprophyticus $(7.01 \%)$.

Table I: Frequency of isolated pathogens from urine $(n=414)$

\begin{tabular}{lcc}
\hline Isolated organisms & Number & Percentage(\%) \\
\hline Escherichia coli & 342 & 82.61 \\
Staphylococcus saprophyticus & 29 & 7.01 \\
Klebsiella & 16 & 3.86 \\
Pseudomonas & 13 & 3.14 \\
Proteus & 5 & 1.45 \\
Enterococci & 6 & 1.21 \\
hamolytic Streptococcus & 2 & 0.48 \\
Staphylococcus aureus & 1 & 0.24 \\
Total & 414 & 100.00 \\
\hline
\end{tabular}

Table II showed the age \& sex distribution of the isolated $S$. saprophyticus. Maximum organisms were isolated from females which was $27(93.10 \%)$ among the $29 \mathrm{~S}$. saprophyticus isolates. Highest (44.82\%) rate of isolation was among female of 18- 45 years age group. Rate of isolation was also higher $(41.38 \%)$ among female of $<18$ years age group.

Table II: Age and sex distribution of $S$. saprophyticus (29 out of 414)

\begin{tabular}{lccc}
\hline Age (in years) & \multicolumn{2}{c}{ Sex } & Total \\
\hline$<18$ & $12(41.38 \%)$ & $02(6.90 \%)$ & $14(48.27 \%)$ \\
$18-45$ & $13(44.82 \%)$ & $00(00 \%)$ & $13(44.83 \%)$ \\
$>45$ & $02(6.90 \%)$ & $00(00 \%)$ & $2(6.90 \%)$ \\
Total & $27(93.10)$ & $02(6.90)$ & $29(100 \%)$
\end{tabular}

The antibiogram of isolated $S$. saprophyticus had been shown in table III. All strains of S. saprophyticus $(100 \%)$ were sensitive to Imipenem. High sensitivity was also observed to gentamicin (86.20\%) and ceftriaxone $(72.41 \%)$. Ciprofloxacin was found to be sensitive against $68.96 \%$ isolates. The sensitivity to other antibiotics varied from $65.51 \%$ to as low as $24.13 \%$. 
Table III: Anti-microbial sensitivity pattern of $S$. saprophyticus $(\mathbf{n}=\mathbf{2 9})$

\begin{tabular}{lcc}
\hline Antibiotic & Sensitive & Resistant \\
\hline Imipenem & $29(100.00 \%)$ & $0(00 \%)$ \\
Gentamicin & $25(86.21 \%)$ & $4(13.79 \%)$ \\
Ceftriaxone & $21(72.41 \%)$ & $8(27.59 \%)$ \\
Ciprofloxacin & $20(68.97 \%)$ & $9(31.03 \%)$ \\
Ceftazidime & $19(65.52 \%)$ & $10(34.48 \%)$ \\
Cephalexin & $16(55.17 \%)$ & $13(44.83 \%)$ \\
Cloxacillin & $16(55.17 \%)$ & $13(44.83 \%)$ \\
Nitrofurantoin & $14(48.28 \%)$ & $15(51.72 \%)$ \\
Tetracycline & $13(44.83 \%)$ & $16(55.17 \%)$ \\
Cotrimoxazole & $12(41.38 \%)$ & $17(58.62 \%)$ \\
Nalidixic acid & $10(34.48 \%)$ & $19(65.52 \%)$ \\
Amoxycillin & $7(24.14 \%)$ & $22(75.86 \%)$ \\
\hline
\end{tabular}

\section{Discussions:}

S. saprophyticus is a leading cause of cystitis in young women and is second only to E. coli as the most frequent causative organism of uncomplicated UTI in women. Significantly more patients infected with $S$. saprophyticus complain of dysuria, urinary frequency, and back pain than do patients infected with Esch. coli ${ }^{23}$. Sometimes immediate and empirical antibiotic therapy is needed and the clinicians rely on their "best guess" etiological agents without microbiological tests. A drug commonly used to treat $S$. saprophyticus infections is ciprofloxacin. If the treatment is not complicated by other infections, the UTI can be cleared in 1-2 days. Unfortunately there is growing resistance of commonly used urinary antibiotics sometimes complicate the situations. So, an antibiotic has to be chosen based on the resistance rate in that geographic area ${ }^{24}$.

The present study emphasizes the rate of isolation of $S$. saprophyticus as a cause of UTI among different age and sex and their resistant pattern against commonly used antibiotics. In this study a total 414 organisms were isolated. Among the total 414 isolates Esch. coli was the most predominant $(82.61 \%)$ organism. This correlates with the findings of other workers $^{25,26}$.

The next common isolate was $S$. saprophyticus (7.01). Similar finding were observed by other workers ${ }^{26,27}$. Young women are more susceptible to $S$. saprophyticus because rectal, vaginal, and urethral colonization by this organism ${ }^{8}$. Of the total 29 S. saprophyticus isolates 27 (93.10\%) were isolated from females. Highest (44.82\%) rate of isolation was among female of 18-45 years age group. Rate of isolation was also more among female of $<18$ years age group which was $41.38 \%$. Young women are more susceptible to genitourinary colonization than are others, and some patients develop infection in association with hormonal influences that occur near or during menstruation. Sexual intercourse promotes colonization and infection. Spermicidals and candidal infections affect the vaginal flora, increasing the risk of colonization and infection by $S$. saprophyticus ${ }^{28}$. $S$. saprophyticus secretes an autolysin that is thought to be involved in binding fibronectin. ${ }^{3}$ S. saprophyticus produce urease, which hydrolyzes urea and produces a derivative of ammonia. This is how the cell metabolizes Nitrogen. Urease activity is known to be an infection causing factor in UTIs ${ }^{29}$.

S. saprophyticus was once well known for its susceptibility to commonly prescribed antibiotics for patients with UTI with the exception of nalidixic acid ${ }^{30}$. The antibiogram of isolated S. saprophyticus shows that all strains of $S$. saprophyticus $(100 \%)$ were sensitive to Imipenem. High sensitivity was also observed to gentamicin $(86.20 \%)$ and ceftriaxone $(72.41 \%)$. Ciprofloxacin is the most frequently prescribed fluoroquinolone for UTIs because of its availability in oral and intravenous formulations. It is well absorbed from oral doses and is rapidly excreted from the body under normal conditions $^{31,32}$. But in this study ciprofloxacin was found to be sensitive against $68.96 \%$ isolates.

The sensitivity to other antibiotics varied from $65.51 \%$ to as low as $24.13 \%$. Similar sensitivity pattern was observed by other workers ${ }^{33}$. Resistance to fluoroquinolones has increased markedly since their introduction for UTI treatment. Many studies world wide as well as in Bangladesh reported a clear increase in ciprofloxacin resistance ${ }^{34} .0 \%$ resistance of $S$. saprophyticus to all the antibiotics was shown in $1976 .{ }^{35} 0 \%$ resistance to Ciprofloxacin was also observed in other studies in Bangladesh between 1992 to 199936,37. The high resistance rates to ciprofloxacin against $S$ saprophyticus, were reported with other authors ${ }^{34}$. High resistance rates $(31.04 \%)$ to ciprofloxacin against $S$ saprophyticus was also seen in the present study. The choice of antimicrobial agents to treat both coagulase-positive and CoNS has become increasingly problematic because of multidrug resistant strains. Increasing trend of antimicrobial resistance is apparently more in $\mathrm{CoNS}^{38}$. The increasing resistance pattern of different antibiotics to $S$. Saprophyticus in this study in comparison to previous ones should make us conscious that time is not far away when we have also worry about antibiotic resistance of S. Saprophyticus.

\section{References}

1. Johnson CC: Defination,classification, \& clinical presentation of Urinary tract infections. Med Clin North Am. March 1991; 75(2):241-243.

2. Gonzalez C.M, Schaeffer A.J. Treatment of urinary tract infection: what's old, what's new, and what works. World J Urol. 1999; 17(6):372-382.) 
3. Widerström, M; Wiström, J; Sjöstedt, A; Monsen, T. "Coagulase-negative staphylococci: update on the molecular epidemiology and clinical presentation, with a focus on Staphylococcus epidermidis and Staphylococcus saprophyticus. European journal of clinical microbiology \& infectious diseases: official publication of the European Society of Clinical Microbiology Jan 2012; 31 (1): 7-20.

4. Torres Pereira A. Coagulase-negative strains of staphylococcus possessing antigen 51 as agents of urinary infection. J Clin Pathol 1962; 15:252-3.

5 Maskell R. Importance of coagulase-negative staphylococci as pathogens in the urinary tract. Lancet 1974; 1:1155-8.

6. Fowler JE. Staphylococcus saprophyticus as the cause of infected urinary calculus. Ann Intern Med 1985;102:3423.

7. Hedman P, Ringertz O. Urinary tract infections caused by Staphylococcus saprophyticus. A matched case control study. J Infect Dis 1991;23:1

8. Joklik WK, Willett HP, Amos BD, Wilfert CM. editors. Zinsser Microbiology. 20 $0^{\text {th }}$ ed. Prientice-Hall International Inc:Appleton \& Lange 1992.414.

9. Latham RH, Running K, Stamm WE. Urinary tract infections in young adult women caused by Staphylococcus saprophyticus. JAMA 1983; 250:3063-6.

10. Hájek, V; Meugnier, H; Bes, M; Brun, Y; Fiedler, F; Chmela, Z; Lasne, Y; Fleurette, J; Freney, J. "Staphylococcus saprophyticus subsp. bovis subsp. nov., isolated from bovine nostrils. International journal of systematic bacteriology. 1996; 46 (3): 792-6.

11 Gupta K, Hooton TM, Wobbe CL, Stamm WE. The prevalence of antimicrobial resistance among uropathogens causing acute uncomplicated cystitis in young women. Int J Antimicrob Agents 1999;11:305-8.

12. Schneider PF, Riley TV. Staphylococcus saprophyticus urinary tract infections: epidemiological data from Western Australia. Eur J Epidemiol 1996;12:51-4.

13. Abrahamsson K, Hansson S, Jodal U, Lincoln K. Staphylococcus saprophyticus urinary tract infections in children. Eur J Pediatr 1993;152:69-71.

14. Glimaker M, Granert C, Krook A. Septicemia caused by Staphylococcus saprophyticus. Scand J Infect Dis 1988; 20:347-845-53.

15. Singh VR, Raad I. Fatal Staphylococcus saprophyticus native-valve endocarditis in an intravenous drug addict. J Infect Dis 1990;162: 783-4.
16. Tolaymat A, Al-Jayousi Z. Staphylococcus saprophyticus urinary-tract infection in male children. Child Nephrol Urol 1991;11:100-2.

17. Hovelius BS, Colleen S, Mardh PA . Urinary tract infections in men caused by Staphylococcus saprophyticus. Scand J Infect Dis 1984;16:37-41.

18. KauffmanCA, Hertz CS, Sheagren JN. Staphylococcus saprophyticus: role in urinary tract infections in men. $\mathrm{J}$ Urol 1983; 130:493-4.

19. Gupta K, Hooton TM, Stamm WE. Increasing Antimicrobial resistance and the management of uncomplicated community acquired Urinary Tract Infections. Ann Intern Med. July 2001; 135(1) :41-50)

20. Drago L, De Vecchi E, Mombelli B, Nicola L, Valli M, Gismondo M.R. Activity of levofloxacin and ciprofloxacin against urinary pathogens. J Antimicrob Chemother. 2001;48(1):37-45.

21. Schaeffer A.J. The expanding role of fluoroquinolones. Am J Med.2002;113 (suppllA):45S-54S.

22. Bauer AW, KirbyWM , Sherria JC, Jurch M. Antibiotic susceptibility method. Am J Clin Path. 1996; 451:493496.

23. Foster RT Sr. Uncomplicated urinary tract infections in women. Obstet Gynecol Clin North Am. Jun 2008; $35(2): 235-48$.

24. Shaqra Q. Occurrence and antibiotic sensitivity of Enterobacteriaceaeisolated from a group of Jordanian patients with community acquired urinary tract infections. Cytobios. 2000; 101(396):15-21.

25. Akhtarun N, Yasmin J, Marium K, Zahidur R. Asymptomatic Bacteriuria among Pregnant Women. Bangladesh J. Anat. 2005; 3(1):26-31

26. Rupp ME; Soper, DE; Archer, GL. "Colonization of the female genital tract with Staphylococcus saprophyticus." Journal of clinical microbiology Nov 1992; 30 (11): 2975-9.

27. Navarre, W. W. and O. Schneewind. Surface proteins of gram-positive bacteria and mechanisms of their targeting to the cell wall envelope. Microbiol. Mol. Biol. Rev. 1999; 63:174-229.

28. Kuroda, M., A. Yamashita, H. Hirakawa, M. Kumano, K. Morikawa, M. Higashide, A. Maruyama, Y. Inose, K. Matoba, H. Toh, S. Kuhara, M. Hattori, and T. Ohta. Whole genome sequence of Staphylococcus 
saprophyticus reveals the pathogenesis of uncomplicated urinary tract infection. Proc. Natl. Acad. Sci. USA 2005.102:13272-13277.

29. Kamberi M, Tsutsumi K, Kotegawa T, et al. Influences of urinary $\mathrm{pH}$ on ciprofloxacin pharmacokinetics in humans and antimicrobial activity in vitro versus those of sparfloxacin. Antimicrob Agents Chemother. 1999;43(3):525-529.

30 . King D.E, Malone R, Lilley S.H. New classification and update on the quinolone antibiotics. Am Fam Physician. 2000;61(9):2741-2748.

31. Shao K, Wang W.P, Li Z.D. Distribution and resistance trends of pathogens from urinary tract infections and impact on management. Zhonghua Nan Ke Xue. 2003; 9 (9):690-692, 696.

32. Kahlmeter G. An international survey of the antimicrobial susceptibility of pathogens from uncomplicated urinary tract infections: the ECO.SENS Project. J Antimicrob Chemother. 2003;51(1):69-76.

33. Begum BA, Paul S, Khan TM, Shafiullah SM, Afroz S, Alam B, Tahmina S, Gazi JU, Lutfor AB . Antibiogram of Urinary Pathogens Isolated in Sir Salimullah Medical College Mitford Hospitals, Dhaka. Sir Salimullah Med Coll J 2008; 16:45-49.
34. Akhtauzzaman C. Urinary tract infections in pregnancy-A bacteriological study.M.Phil (Microbiology thesis) 2002, BSMMU.

35. Razzaque SMA, Rahman MA: bacteriuria and UTI in pregnancy. BMRC Bull. Dec 1977; vo 13 (2): 145-148.

36. Onifade EO, Nwobu RAU, Bamidele EO, Okanume CA: pathogens and antibiotic susceptibility profiles in the urinary tract. East African Medical Journal. 1992 . vol 69 (10) : 587-590.

37 . Sharif MNH: Diagnosis and detection of UTI with special reference to $E$. coli O- serogroup. MD ( Nephrology thesis) .1999, Dhaka University.

38. Lowy FD. Staphylococcal Infections. In: Fauci AS, Kasper DL, Longo DL editors. Harrison's Principles of Internal Medicine. 17th ed. The United States of America: The McGraw-HillCompanies;2008;p.879. 